\title{
Doxycycline down-regulates matrix metalloproteinase expression and inhibits NF- $\kappa$ B signaling in LPS-induced PC3 cells
}

\author{
Deniz Ogut ${ }^{1}$, Buket Reel ${ }^{1}$, Ceren Gonen Korkmaz ${ }^{1}$, Mehmet Zuhuri Arun ${ }^{1}$, \\ Serap Cilaker Micili², Bekir Ugur Ergur ${ }^{2}$
}

\author{
${ }^{1}$ Department of Pharmacology, Faculty of Pharmacy, Ege University, Bornova-Izmir, Turkey \\ ${ }^{2}$ Department of Histology and Embryology, School of Medicine, Dokuz Eylul University, \\ Inciralti-Izmir, Turkey
}

\begin{abstract}
Introduction. Matrix metalloproteinase enzymes (MMPs) play important role in inflammation, malignant cell proliferation, invasion and angiogenesis by mediating extracellular matrix degradation. Doxycycline, a synthetic tetracycline, behaves as a MMP inhibitor at a subantimicrobial dose and inhibits tumor cell proliferation, invasion and angiogenesis. The aberrant activity of nuclear factor kappa B (NF- $\kappa \mathrm{B})$ causes activation of MMPs and thereby proliferation and invasion of cancer cells. The aim of this study was to investigate the effects of doxycycline on the expression of MMPs in lipopolysaccharide (LPS)-induced PC3 human prostate cancer cells and the possible role of NF- $\kappa \mathrm{B}$ signaling. Material and methods. PC 3 cells were incubated with LPS $(0.5 \mu \mathrm{g} / \mathrm{mL})$ for $24 \mathrm{~h}$ in the presence or absence of doxycycline $(5 \mu \mathrm{g} / \mathrm{mL})$. The effects of LPS and doxycycline on the expressions of MMP-2, MMP-8, MMP-9, MMP-10, NF- $\kappa \mathrm{B} / \mathrm{p} 65$, I $\kappa \mathrm{B}-\alpha, \mathrm{p}-\mathrm{I} \kappa \mathrm{B}-\alpha$, IKK- $\beta$ were examined by Western blotting and immunohistochemistry in PC 3 cells. Furthermore, relative proteinase activities of MMP-2 and MMP-9 were determined by gelatin zymography.

Results. LPS increased expression and activity of MMP-9 and expression of MMP-8, MMP-10, NF- $\kappa$ B/p65, $\mathrm{p}-\mathrm{I} \kappa \mathrm{B}-\alpha, \mathrm{IKK}-\beta$ and doxycycline down-regulated its effects with the exception of MMP-10 expression. The expression of MMP-2 and I $\kappa \mathrm{B}-\alpha$ was affected by neither LPS nor doxycycline.

Conclusions. Our findings indicate that doxycycline inhibits the expression of various MMPs and NF- $\kappa$ B signaling may play a role in the regulation of MMPs expression in LPS-induced PC3 human prostate cancer cells. (Folia Histochemica et Cytobiologica 2016, Vol. 54, No. 4, 171-180)
\end{abstract}

Key words: prostate cancer; PC3 cells; MMPs; doxycycline; NF- $\kappa \mathrm{B}$; immunohistochemistry; Western blotting; zymography

\section{Introduction}

Prostate cancer is the third cause of cancer-associated death in men after lung cancer in developed countries [1-3]. Although early detection of prostate cancer is crucial, several biomarkers for early screening are still controversial $[4,5]$. Over $70 \%$ of the patients are cured

\footnotetext{
Correspondence address: B. Reel, Ph.D.

Ege University, Faculty of Pharmacy

Department of Pharmacology

35100 Bornova-Izmir, Turkey

tel.: +902323113286

e-mail: buket.reel@ege.edu.tr
}

after various primary treatment options such as surgery, radiotherapy and androgen-deprivation therapy $[2,6]$. However, recurrence which occurs in $34 \%$ of the patients within 5 years and in $46 \%$ of the patients after 10 years limits management of the disease and prevents better cancer control and lower morbidity $[2,6]$. Therefore, understanding the underlying mechanism of the disease may be critical in the development of novel approaches for appropriate diagnosis and treatment.

Matrix metalloproteinases (MMPs) are a family of zinc-dependent endopeptidases which degrade extracellular matrix (ECM) components and play an essential role in the processes of cancerogenesis including tumor growth, angiogenesis, invasion and me- 
tastasis [7, 8]. MMPs were divided into subgroups of collagenases(MMPs-1,-8,-13), gelatinases(MMPs-2,-9), stromelysins (MMPs-3, -10, -11), membrane-type MMPs (MMPs-14 to -17), and other MMPs (e.g., MMP-12) [9]. Activity of MMPs is tightly regulated by endogenous tissue inhibitors of MMPs (TIMPs) [9]. In numerous clinical and experimental studies related to various types of cancers, overexpression of MMPs, in particular MMP-2 and MMP-9 (gelatinases) and low levels of TIMPs were reported [7, 10, 11]. Accordingly, targeting MMPs may be an efficient therapeutic strategy to control tumorigenesis, invasion and metastasis [12].

Tetracyclines at the subantimicrobial dose inhibit MMPs by the mechanism independent from their antimicrobial activity [13]. They inhibit MMPs via chelating the catalytic $\mathrm{Zn}^{+2}$ ion in the active site of MMP molecule [14].

Tetracyclines have high affinity to bone tissue which serves as a drug reservoir. They also inhibit metastasis of cancer cells to the bone and protect connective tissue from excessive breakdown mediated by MMPs $[2,15$, 16]. Doxycycline at subantimicrobial dose is the unique MMP inhibitor which was approved by Food and Drug Administration for the treatment of periodontal diseases [17, 18]. However, molecular mechanisms responsible for the inhibitory effect of doxycycline on MMPs have yet not been fully understood.

Nuclear Factor Kappa B (NF- $\kappa \mathrm{B}$ ) belongs to a family of transcription factors which provide a pivotal link between inflammation and cancer $[19,20]$. NF- $\kappa \mathrm{B}$ activity is regulated by two main pathways which are known as the classical (canonical) pathway and the alternative one. The classical pathway plays a crucial role in the control of inflammation. In this pathway, Rel A (p65)-p50 dimer which consists of two members of NF$-\kappa \mathrm{B}$ family exists in an inactive form bound to inhibitory $\mathrm{I} \kappa \mathrm{B}-\alpha$ (inhibitor of kappa B- $\alpha$ ) molecule. Phosphorylation of the IKK ( $\mathrm{I} \kappa \mathrm{B}$ kinase) complex that consists of $\operatorname{IKK} \alpha, \operatorname{IKK} \beta$, and IKK $\gamma$, leads to the phosphorylation of inhibitory $\mathrm{I} \kappa \mathrm{B}-\alpha$ molecule and to the release of Rel A (p65)-p50 from Rel A (p65)-p50-I $\kappa$ B- $\alpha$ complex. Then, $\mathrm{I} \kappa \mathrm{B}-\alpha$ is marked for degradation by the proteasome pathway and Rel A (p65)-p50 translocates to cell nucleus. In nucleus, Rel A (p65)-p50 binds to the promoter region of target genes and induces expression of NF- $\kappa \mathrm{B}$-related genes. For the termination of $\mathrm{NF}-\kappa \mathrm{B}$ signaling, cytoplasmic synthesis of new $\mathrm{I} \kappa \mathrm{B}-\alpha$ is necessary. The new $\mathrm{I} \kappa \mathrm{B}-\alpha$ enters the nucleus and binds to the Rel A (p65)-p50. This causes the dissociation of Rel A (p65)-p50-I $\kappa \mathrm{B}-\alpha$ complex from DNA and its re-exportation to the cytoplasm [21-23].

Increased activation of $\mathrm{NF}-\kappa \mathrm{B}$ signaling through proinflammatory stimuli in tumor microenvironment has been demonstrated to stimulate proliferation, migration and metastasis of cancer cells and inhibit apoptosis in many human malignancies including prostate cancer [20, 23, 24]. More importantly, in breast cancer patients NF- $\kappa \mathrm{B}$ activation promoted up-regulation of MMP-9 which was closely associated with shorter lifespan [25]. All of the studies related to the NF- $\kappa \mathrm{B}$-dependent-MMP regulation in prostate cancer focused on the regulation of gelatinases (MMP-2 and -9) [23, 26]. However, the role of NF- $\kappa$ B activation in the gene regulation of MMPs from the subgroups of collagenases and stromelysins in prostate cancer has not been studied yet. Additionally, the modulating effects of lipopolysaccharide (LPS) which is an inflammatory stimulus on NF- $\kappa \mathrm{B}$ translocation and regulation of MMPs in prostate cancer remains to be investigated.

On the other hand, various anticancer agents were reported to inhibit NF- $\kappa$ B signaling-mediated MMP up-regulation in prostate cancer [27, 28]. Similarly, doxycycline was shown to suppress NF- $\kappa \mathrm{B}$ signaling in LPS-treated microglial cells [29]. However, the effects of doxycycline on NF- $\kappa \mathrm{B}$ signaling and regulation of MMP expression in prostate cancer have yet not been examined.

Hence, in the current study, we investigated the effects of doxycycline at subantimicrobial dose on the regulation of the expression of MMPs from diverse subgroups including gelatinases, collagenases and stromelysins, and a possible contribution of NF- $\kappa \mathrm{B}$ signaling to this expression in LPS-induced PC3 human prostate cancer cells.

\section{Material and methods}

Reagents. Cell culture media (RPMI 1640), fetal bovine serum (FBS) and L-glutamine were obtained from Gibco, Thermo Fisher Scientific, Gran Island, NY, USA. Electrophoresis reagents and LPS (Lipopolysaccharides isolated from E. coli 026:B6, L2654) were purchased from Sigma-Aldrich, St. Louis, MO, USA. The chemiluminescence visualization reagent ImmunoCruz was from SantaCruz Biotechnology Inc., Santa Cruz, CA, USA. The molecular weight marker (PageRuler Plus Prestained Protein Ladder) was obtained from Thermo Fisher Scientific. Doxycycline hyclate (PubChem CID:54732805) was purchased from Kaifeng Pharmaceutical Group Co., Ltd. Kaifeng, Henan, China. Primary antibodies were detailed in Table S.1. Doxycycline and LPS solutions were freshly prepared each time by dissolving in sterile water and then sterilized using a syringe filter (Minisart, Goettingen, Germany).

Cell culture. PC3 cell line was a kind gift from Dr. K.S. Korkmaz, Ege University, Izmir, Turkey (the cell line was 
obtained from American Type Culture Collection; ATCC). The cells were routinely maintained in RPMI 1640 medium supplemented with $10 \%$ FBS, $1 \%$ penicillin/streptomycin $(5 \mathrm{mg} / \mathrm{mL})$ and $1 \%$ L-glutamine $(200 \mathrm{mM})$ in a humidified atmosphere containing $5 \% \mathrm{CO}_{2}$ at $37^{\circ} \mathrm{C}$.

Induction and treatment of the cells. Cells were seeded into 12 -well plates. When they became confluent, they were induced with $0.5 \mu \mathrm{g} / \mathrm{mLLPS}[30,31]$ in the presence or absence of $5 \mu \mathrm{g} / \mathrm{mL}$ doxycycline [32] for $24 \mathrm{~h}$. The optimal concentration of LPS and doxycycline were determined in consideration of our preliminary studies (data not shown). Uninduced and untreated cells were maintained as control cells for the same period of time. In all experiments doxycycline and LPS were added into the culture media at the same time. Cells were collected and stored at $-80^{\circ} \mathrm{C}$ for further investigations.

Cell lysis and protein extraction. Cells were resuspended in $250 \mu \mathrm{L}$ of lysis buffer (20 mM HEPES $\mathrm{pH}=7.4,0.1 \%$ Triton X-100, $0.2 \mathrm{mM}$ EDTA, $300 \mathrm{mM} \mathrm{NaCl}$ ) then collected from culture plates and transferred to Eppendorf tubes. The tubes were incubated on ice and centrifuged at 13,000 rpm for $30 \mathrm{~min}$ and then supernatants were collected. Protein concentration in lysates was measured fluorometrically by using Quant-IT protein assay kit (Invitrogen, Carlsbad, CA, USA) according to the manufacturer's protocol.

Western blotting. Under standard conditions, $25 \mu \mathrm{g}$ of protein from each cell extract was loaded to $10 \%$ SDS-PAGE gels and separated by BioRad vertical electrophoresis system (Mini-PROTEAN Tetra Cell, BioRad Cat No:1658001, Hempstead, UK). Then, the gels were transferred to PVDF membrane (Amersham, Buckinghamshire, UK) by semi-dry transfer blotter (VWR, V20-SDB, Tingalpa, Australia). PVDF membranes were blocked with blocking solution (PBS-T, Phosphate-Buffered Saline solution containing 5\% dry milk and $0.1 \%$ Tween 20 ) for 1 hour. Incubations with primary and secondary antibody were carried out using PBS-T containing $5 \%$ dry milk at $4{ }^{\circ} \mathrm{C}$ overnight and immunoblotted with primary antibodies. Primary antibodies used were rabbit antibodies specific for MMP-9, MMP-10, MMP-8, NF- $\kappa$ B/p65, I $\kappa$ B- $\alpha$, phosphorylated $\mathrm{I} \kappa \mathrm{B}-\alpha(\mathrm{p}-\mathrm{I} \kappa \mathrm{B}-\alpha)$, IKK- $\beta, \beta$-actin and mouse antibody specific for MMP-2. Membranes were developed using horseradish peroxidase-coupled secondary antibody and Western blotting (WB) luminol reagent (ImmunoCruz). Western blots were photographed by Fusion FX7 (Vilbert Lourmat, Collégien, France) and optical densities of blotting images were quantified by ImageJ software (ImageJ 1.46r, National Institutes of Health, Bethesda, MD, USA) and were normalized with $\beta$-actin.

Gelatin zymography. Equal protein concentration $(25 \mu \mathrm{g})$ of each zymography sample was loaded into $10 \%$ polyacryl- amide gels containing $2 \mathrm{mg} / \mathrm{mL}$ gelatin and were subjected to SDS-polyacrylamide gel electrophoresis. Then, SDS was removed from the gels and gels were incubated at $37^{\circ} \mathrm{C}$ for $48 \mathrm{~h}$ in incubation buffer $(50 \mathrm{mM}$ Tris- $\mathrm{HCl}, \mathrm{pH} 8.0,50 \mathrm{mM}$ $\mathrm{NaCl}, 10 \mathrm{mM} \mathrm{Ca} \mathrm{Cl}_{2}$, and $0.05 \%$ Triton $\left.\mathrm{X}-100\right)$. After the incubation period, gels were stained in $0.2 \%$ Coomassie Brilliant Blue. Images of the gels were photographed by using Fusion FX7. Gelatinase activity was detected as clear bands on dark backgrounds. Densitometric analysis of the bands was performed using ImageJ software.

Immunohistochemistry. Cell medium and cell suspension were added on to coverslips placed in six well plates. The cells were kept in a humidified atmosphere containing 5\% $\mathrm{CO}_{2}$ at $37^{\circ} \mathrm{C}$ for $24 \mathrm{~h}$ to allow cells to adhere to coverslips. Then, the adhered cells were incubated with LPS and/or doxycycline for the next $24 \mathrm{~h}$ in a humidified atmosphere containing $5 \% \mathrm{CO}_{2}$ at $37^{\circ} \mathrm{C}$. Some of the coverslips were kept as control cells incubated without LPS and doxycycline. After treatment period, cell media were removed and cells were fixed in $96 \%$ ethanol for $15 \mathrm{~min}$. Then, ethanol was removed, cells on the cover slips were rehydrated through alcohol series and then washed with distilled water. Following these steps, the cells were treated with a solution of $0.125 \%$ trypsin (diluted with Digest All 2A; 00-3008, Zymed, San Francisco, CA, USA) for $5 \mathrm{~min}$ at $37^{\circ} \mathrm{C}$. Then cells were incubated in a solution of $3 \% \mathrm{H}_{2} \mathrm{O}_{2}$ for $5 \mathrm{~min}$ and with normal serum blocking solution. Coverslips were first incubated in a humidified chamber for $18 \mathrm{~h}$ at $4^{\circ} \mathrm{C}$ with primary antibodies against MMP-8, MMP-9, NF- $\kappa$ B/p65, IKK- $\beta$, p-I $\kappa$ B- $\alpha$ and thereafter with biotinylated $\mathrm{IgG}$, and then with streptavidin conjugated to horseradish peroxidase according to kit instructions (85-9043, Invitrogen). Finally, coverslips were stained with DAB (diaminobenzidine, 1718096, Roche, Mannheim, Germany) and counter-stained with Mayer's hematoxylin. After that, images of cells were captured by using a BX-51 light microscope (Olympus, Tokyo, Japan) equipped with a high-resolution video camera (Olympus DP-71). The intensity of immunopositivity for each protein was evaluated using immunoscoring scale by two histologists, who were blinded to the treatment of the samples. The immunoscoring was performed semi-quantitatively, by considering the degree of positive cytoplasmic staining of cells and by scoring according to the following scale: negative (0), weak (1), moderate (2) and strong (3) immunoreactivity. A mean score was calculated for each sample. Then, mean scores were used to categorize immunopositivity as weak $(<1.5)$ or strong $(>1.5)$.

Statistical analyses. All data were expressed as mean \pm S.E.M. Statistical analyses of the data were performed using SPSS software for Microsoft Windows (IBM SPSS PASW Statistics 19 Fix Pack 1 Amos 19, Chicago, IL, USA). The statistical analyses for the data from WB and 

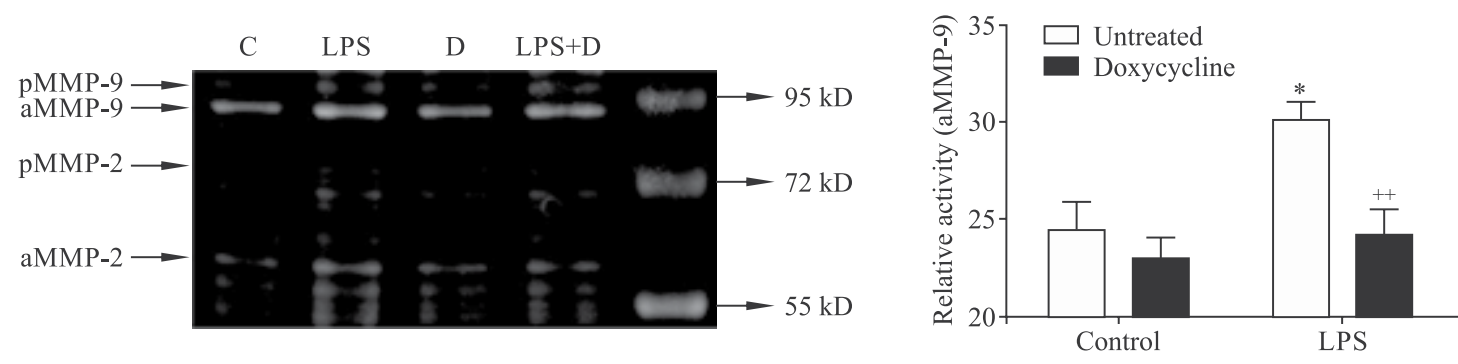

Figure 1. Effects of LPS and doxycycline treatment on gelatinase (MMP-2 and -9) expressions and activities in PC3 cells. Gelatinase expressions and activities were determined by gelatin zymography after induction with LPS and doxycycline treatment for $24 \mathrm{~h}$ and were shown by a representative zymogram. Relative proteinase activity of active MMP-9 was expressed as mean \pm SEM $(\mathrm{n}=7) .{ }^{*} P \leq 0.05$, uninduced (LPS-) control PC3 cells versus LPS-induced (LPS,$\left.+ 0.5 \mu \mathrm{g} / \mathrm{mL}\right)$ control cells; ${ }^{++} P \leq 0.01$, LPS-induced (LPS +$)$ control cells versus LPS-induced (LPS +$)$ and doxycycline $(5 \mu \mathrm{g} / \mathrm{mL})$ treated PC3 cells; paired Student's $t$-test. Abbreviations: C — control; D — doxycycline; LPS — LPS-induced; LPS +D — LPS-induced and doxycycline-treated; aMMP — active MMP; pMMP — proMMP

gelatin zymography were carried out using paired Student's t-test. Chi-square test was performed to evaluate the statistical difference of immunostaining between the groups. $P \leq 0.05$ was considered statistically significant.

\section{Results}

\section{Effects of LPS and doxycycline on the expression and activities of gelatinases}

We examined the effects of concomitant LPS $(0.5 \mu \mathrm{g} / \mathrm{mL})$ and doxycycline $(5 \mu \mathrm{g} / \mathrm{mL})$ treatment for $24 \mathrm{~h}$ on gelatinases (MMP-2 and MMP-9) by gelatin zymography and WB analysis in PC3 cells. In zymogram, we determined barely visible bands of lysis representing pro MMP-9 and pro MMP-2 at molecular positions of $97 \mathrm{kDa}$ and $72 \mathrm{kDa}$, respectively, and the active MMP-2 at molecular position of $68 \mathrm{kDa}$ (Figure 1). Bands of lysis of both pro MMP-9 and pro MMP-2 as well as active MMP-2 were too faint for efficient quantitation in PC3 cells.

Gelatin zymography analysis demonstrated that incubation with LPS for $24 \mathrm{~h}$ significantly increased active MMP-9 level in LPS-induced PC3 cells (Figure 1). Doxycycline treatment for $24 \mathrm{~h}$ significantly inhibited this effect (Figure 1). However, doxycycline treatment for the same period had no effect on PC3 cells that were not incubated with LPS (Figure 1)

The expression of MMP-9 was also studied by WB analysis. Consonantly with our zymography findings, the WB results showed that MMP-9 expression was significantly up-regulated in LPS-induced cells compared to non-induced control cells (Figure 2). However, doxycycline treatment significantly inhibited MMP-9 expression in LPS-induced cells (Figure 2). In parallel with the data from gelatin zymography analysis, WB results also demonstrated that MMP-2 expression was not affected by either induction with LPS or doxycycline treatment in PC3 cells (Figure 2).

\section{Immunohistochemical analysis of MMP-9 expression in PC3 cells}

To confirm the effects of induction with LPS and doxycycline treatment on MMP-9 expression, we evaluated the intensity of positive staining of MMP-9 by conducting immunohistochemical (IHC) staining and immunoscoring.

The data showed that LPS caused a significant increase in the intensity rate of positive immunostaining of cells with an anti-MMP-9 antibody, but doxycycline significantly decreased immunopositivity of MMP-9 in LPS-induced PC3 cells (Table 1, Figure 3). Doxycycline did not affect MMP-9 expression in control, LPS-uninduced PC3 cells (Table 1, Figure 3). These results indicate that doxycycline inhibits LPS-induced expression and activity of MMP-9 (gelatinase-2) in PC3 prostate cancer cells.

\section{Effects of LPS and doxycycline on the expression of MMP-8 and MMP-10}

WB findings evidenced that LPS stimulated MMP-8 expression but doxycycline treatment for $24 \mathrm{~h}$ significantly down-regulated MMP-8 expression in LPS-induced PC3 cells. Doxycycline treatment for $24 \mathrm{~h}$ did not change MMP-8 expression level in uninduced PC3 cells (Figure 2).

WB showed that LPS significantly up-regulated MMP-10 expression, while doxycycline treatment did not change MMP-10 expression level in LPS-induced PC3 cells (Figure 2).

In addition, we assessed MMP-8 expression by performing IHC staining and immunoscoring 


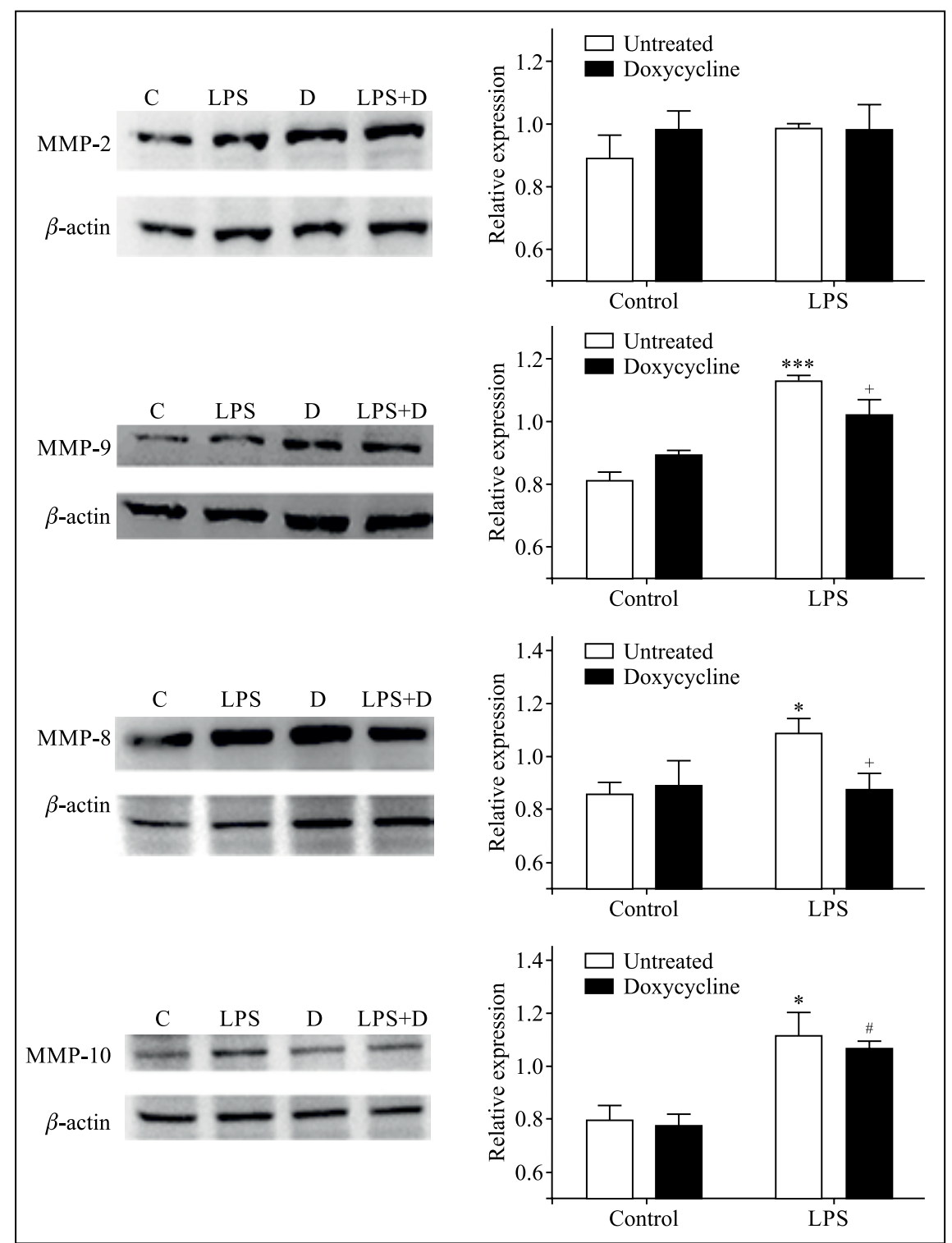

Figure 2. Effects of $0.5 \mu \mathrm{g} / \mathrm{mL}$ LPS and $5 \mu \mathrm{g} / \mathrm{mL}$ doxycycline treatment for $24 \mathrm{~h}$ on the expressions of MMP-2, $-9,-8$ and -10 in PC3 cells. Expression of MMP-2, -9, -8, -10 on Western blotting after induction with LPS and doxycycline treatment for $24 \mathrm{~h}$ were shown by representative Western blots. Relative expression of MMP-2, -9, -8 and -10 was expressed as mean \pm SEM $(\mathrm{n}=5$ or 6$) .{ }^{*} P \leq 0.05,{ }^{* * *} P \leq 0.001$ uninduced (LPS-) control versus LPS-induced (LPS,$\left.+ 0.5 \mu \mathrm{g} / \mathrm{mL}\right) \mathrm{control}$; ${ }^{+} P \leq 0.05$, LPS-induced (LPS +$)$ control versus LPS-induced (LPS +$)$ doxycycline $(5 \mu \mathrm{g} / \mathrm{mL})$ treated PC 3 cells, ${ }^{\#} P \leq 0.05$ uninduced (LPS-) doxycycline versus LPS-induced (LPS+) doxycycline-treated PC3 cells; paired Student's $t$-test. Abbreviations as in the description of Figure 1.

for confirmation. In parallel with the WB results, IHC analysis revealed that positive cytoplasmic staining of cells with an anti-MMP-8 antibody significantly increased in LPS-induced cells (Table 1, Figure 3). However, intensity of MMP-8 immunostaining significantly declined with doxycycline treatment for $24 \mathrm{~h}$ in LPS-induced PC3 cells (Table 1, Figure 3).

\section{Effects of LPS and doxycycline on IKK/I $\kappa B / N F-\kappa B$ axis}

In order to determine the effects of LPS and doxycycline on NF- $\kappa \mathrm{B}$ signaling pathway proteins, we examined the expressions of $\mathrm{NF}-\kappa \mathrm{B} / \mathrm{p} 65$, IKK- $\beta$, $\mathrm{I} \kappa \mathrm{B}-\alpha$ and $\mathrm{p}-\mathrm{I} \kappa \mathrm{B}-\alpha$ in the presence or absence of LPS and/or doxycycline by performing WB analysis and IHC staining. 
Table 1. Immunopositivity scores of anti-MMP-8, anti-MMP-9, anti-NF- $\kappa$ B, anti-IKK- $\beta$ and anti-p-I $\kappa$ B- $\alpha$ staining in PC3 cells after induction with LPS and treatment with doxycycline for 24 hours

\begin{tabular}{|l|c|c|c|c|}
\hline & $\begin{array}{c}\text { Control PC3 } \\
\text { cells }\end{array}$ & $\begin{array}{c}\text { Doxycycline-treated } \\
\text { PC3 cells }\end{array}$ & $\begin{array}{c}\text { LPS-induced } \\
\text { PC3 cells }\end{array}$ & $\begin{array}{c}\text { LPS-induced and doxycycline-treated } \\
\text { PC3 cells }\end{array}$ \\
\hline MMP-8 & $0.467 \pm 0.133$ & $0.400 \pm 0.131$ & $2.133 \pm 0.165^{\mathrm{a}}$ & $1.333 \pm 0.126^{\mathrm{b}}$ \\
\hline MMP-9 & $0.600 \pm 0.131$ & $0.600 \pm 0.131$ & $2.533 \pm 0.133^{\mathrm{a}}$ & $1.467 \pm 0.133^{\mathrm{b}}$ \\
\hline NF- $\kappa$ B & $0.400 \pm 0.131$ & $0.400 \pm 0.131$ & $2.267 \pm 0.182^{\mathrm{a}}$ & $1.467 \pm 0.133^{\mathrm{b}}$ \\
\hline IKK- $\beta$ & $0.467 \pm 0.133$ & $0.467 \pm 0.133$ & $2.067 \pm 0.118^{\mathrm{a}}$ & $1.067 \pm 0.067^{\mathrm{b}}$ \\
\hline p-I $\boldsymbol{\kappa} \mathbf{B}-\alpha$ & $0.667 \pm 0.126$ & $0.533 \pm 0.133$ & $2.133 \pm 0.165^{\mathrm{a}}$ & $1.333 \pm 0.126^{\mathrm{b}}$ \\
\hline
\end{tabular}

PC3 cells were stained immunohistochemically as described in Material and methods. Immunopositivity scores are expressed as mean \pm SEM $(n=3)$.

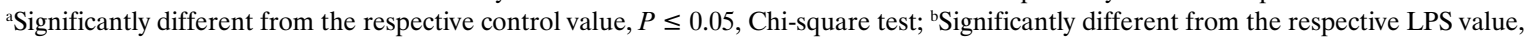
$\mathrm{P} \leq 0.05, \chi^{2}$ test.

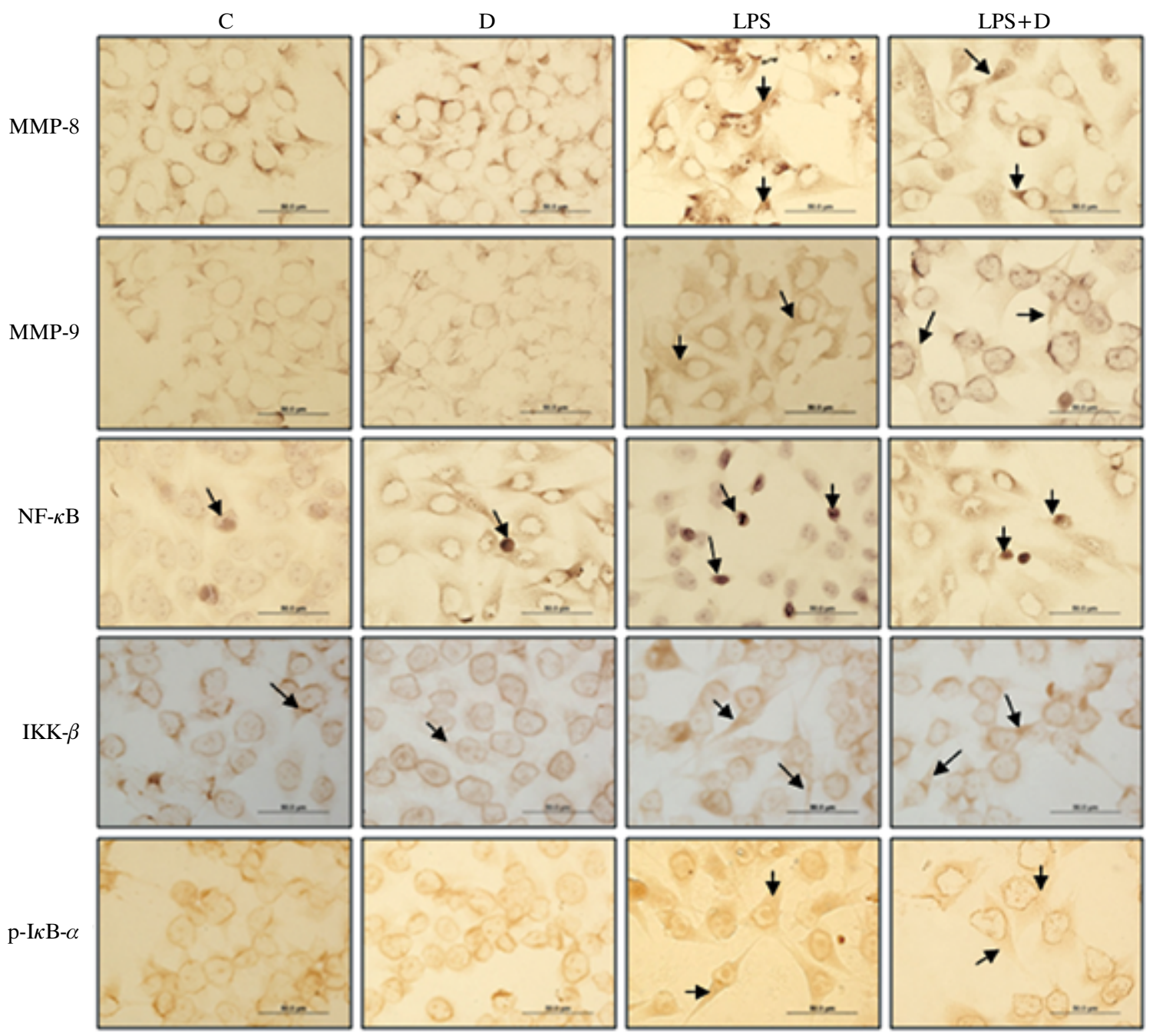

Figure 3. Representative photomicrographs of the immunohistochemical demonstration of anti-MMP-8, anti-MMP-9, anti-NF- $\kappa \mathrm{B}$, anti-IKK- $\beta$, anti-I $\kappa \mathrm{B}-\alpha$ and anti-p-I $\beta \mathrm{B}-\alpha$ in PC3 cells after induction with LPS and doxycycline treatment for $24 \mathrm{~h}$. Cells were cultured and stained immunohistochemically as described in Material and methods. Arrows point out immunopositive staining, magnification $\times 40$, bar $50 \mu \mathrm{m}$. Abbreviations as in the description of Figure 1 .

WB results demonstrated that induction with LPS significantly up-regulated NF- $\kappa \mathrm{B} / \mathrm{p} 65$ expression in PC3 cells and doxycycline significantly suppressed this effect (Figure 4). Moreover, also IKK- $\beta$ expression was significantly up-regulated by LPS. Although doxycycline tended to down-regulate IKK- $\beta$ expression 


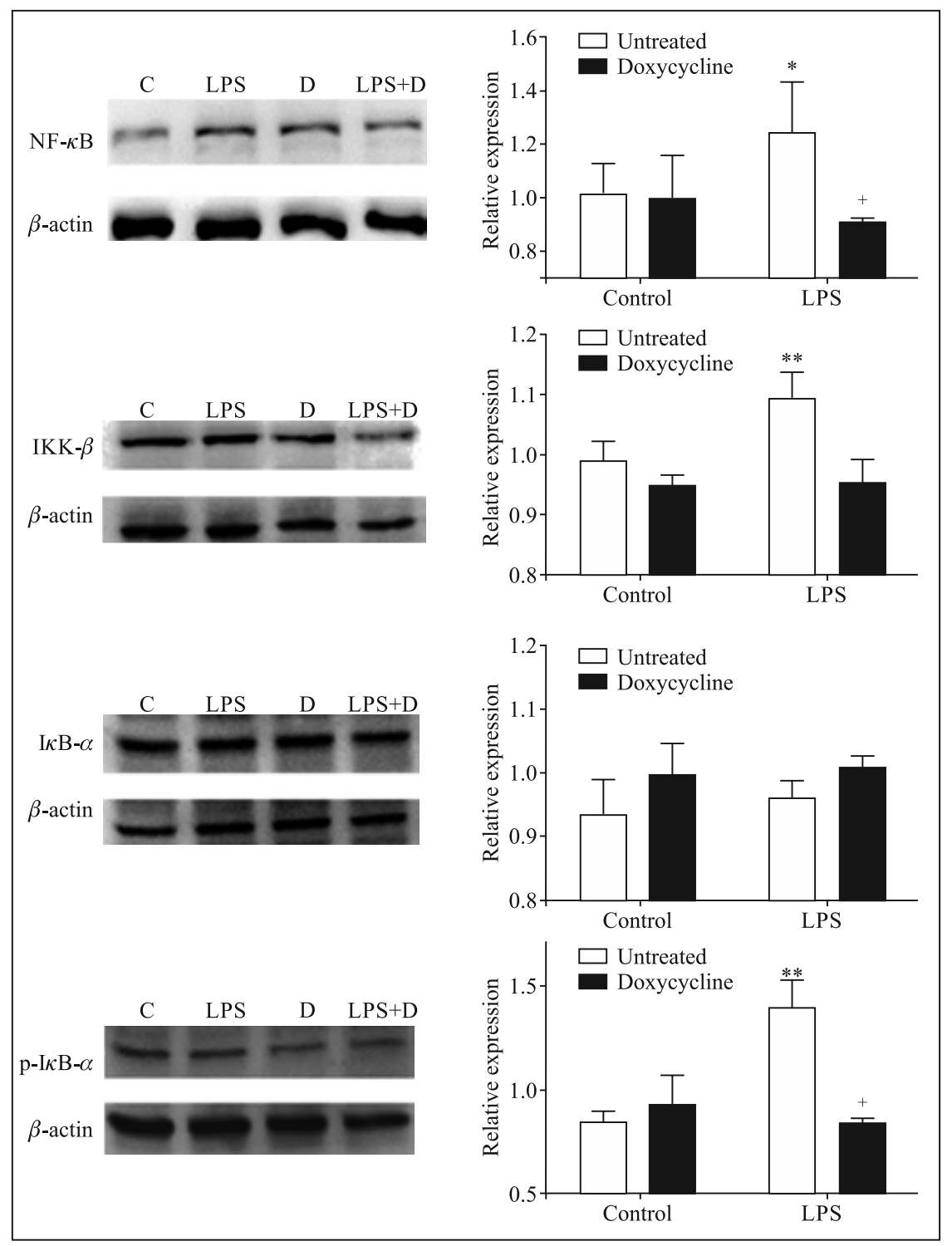

Figure 4. Effects of LPS and doxycycline treatment on the expressions of NF- $\kappa \mathrm{B} / \mathrm{p} 65$, IKK- $\beta$, I $\kappa \mathrm{B}-\alpha$ and p-I $\kappa \mathrm{B}-\alpha$ in PC3 cells. Expressions of NF- $\kappa \mathrm{B} / \mathrm{p} 65$, IKK- $\beta, \mathrm{I} \kappa \mathrm{B}-\alpha$ and $\mathrm{p}-\mathrm{I} \kappa \mathrm{B}-\alpha$ on Western blot after induction with LPS and doxycycline treatment for $24 \mathrm{~h}$ were shown by representative Western blots. Relative expression of NF- $\kappa \mathrm{B} / \mathrm{p} 65$, IKK- $\beta$, I $\kappa \mathrm{B}-\alpha$ and $\mathrm{p}-\mathrm{I} \kappa \mathrm{B}-\alpha$ were expressed as mean $\pm \mathrm{SEM}(\mathrm{n}=4-8) .{ }^{*} P \leq 0.05,{ }^{* *} P \leq 0.01$ uninduced (LPS-) control versus LPS-induced (LPS,$+ 0.5 \mu \mathrm{g} / \mathrm{mL})$ control; ${ }^{+} P \leq 0.05$, LPS-induced (LPS + ) control versus LPS-induced (LPS +$)$ doxycycline $(5 \mu \mathrm{g} / \mathrm{mL})$ treated PC3 cells; paired Student's $t$-test. Abbreviations as in the description of Figure 1.

level, this effect was not statistically significant in LPS-induced PC3 cells (Figure 4).

WB analyses showed that $\mathrm{I} \kappa \mathrm{B}-\alpha$ expression was not affected by either induction with LPS or doxycycline treatment in PC3 cells (Figure 4). WB analyses also showed that $\mathrm{p}-\mathrm{I} \kappa \mathrm{B}-\alpha$ expression was significantly up-regulated by LPS; however, doxycycline inhibited the p-I $\kappa \mathrm{B}-\alpha$ up-regulation (Figure 4).

To corroborate the data from WB experiments, we assessed the immunopositive staining scores for $\mathrm{NF}-\kappa \mathrm{B} / \mathrm{p} 65$, IKK- $\beta$ and $\mathrm{p}-\mathrm{I} \kappa \mathrm{B}-\alpha$. We observed that immunopositive staining scores of NF- $\kappa \mathrm{B} / \mathrm{p} 65$, IKK- $\beta$ and $\mathrm{p}-\mathrm{I} \kappa \mathrm{B}-\alpha$ were significantly higher in LPS-induced cells than the scores in uninduced control cells (Table 1, Figure 3).

We also observed more intense immunostaining for NF- $\kappa \mathrm{B} / \mathrm{p} 65$ in the nuclei of LPS-induced cells, which is the landmark of increased nuclear translocation of NF- $\kappa$ B (Figure 3). IHC analyses also revealed that doxycycline treatment significantly decreased immunopositive staining and immunopositive scores for $\mathrm{NF}-\kappa \mathrm{B} / \mathrm{p} 65, \mathrm{IKK}-\beta$ and $\mathrm{p}-\mathrm{I} \kappa \mathrm{B}-\alpha$ in LPS-induced PC3 
cells (Table 1, Figure 3 ). We also observed apparently impaired staining in cell nucleus where NF- $\kappa \mathrm{B} / \mathrm{p} 65$ is translocated in LPS-induced doxycycline-treated cells compared with LPS-induced control cells (Figure 3).

\section{Discussion}

In this study, we investigated the effects of doxycycline at subantimicrobial dose on the regulation of MMPs from diverse subgroups and the contribution of NF- $\kappa \mathrm{B}$ signaling as a possible underlying mechanism in LPS-induced PC3 human prostate cancer bone metastasis cells. In this context, we evaluated the expression and activity of proteinases representing different subgroups of MMPs: MMP-2/-9 (gelatinases), expression of MMP-8 (collagenases) and MMP-10 (stromelysins) in the presence or absence of doxycycline in LPS-induced or uninduced PC 3 cells. We also have examined in these cells the expression levels of the members of the classical $\mathrm{NF}-\kappa \mathrm{B}$ activation pathway including NF- $\kappa \mathrm{B} / \mathrm{p} 65$, activator kinase IKK- $\beta$, which has a pivotal role in NF- $\kappa \mathrm{B}$ activation, and inhibitor IkB- $\alpha$.

We found that the expression of NF- $\kappa \mathrm{B} / \mathrm{p} 65$, IKK- $\beta$ and $\mathrm{p}-\mathrm{I} \kappa \mathrm{B}-\alpha$ was significantly up-regulated in parallel with the increased expression of MMP-9, -8 and -10 in LPS-induced PC3 cells. These results for the first time indicate that LPS-induced up-regulation of MMP-8, -9 and -10 from different subgroups of MMPs may be at least partly mediated by the activation of NF- $\kappa \mathrm{B}$ signaling in PC3 human prostate cancer cells.

Consistent with our evidence, a recent study reported that LPS-induced TLR4 activation leads to NF- $\kappa$ B activation and up-regulation of MMP- 2 and -9 in colorectal cancer cells [33]. Similarly, it was previously found that metadherin, a newly identified oncogene inhibits LPS-induced NF- $\kappa$ B activation and downstream MMP-9 regulation in the migration and invasion of breast cancer cells [34]. In line with these reports, UDN glycoprotein isolated from Ulmus davidiana Nakai was demonstrated in LPS-induced colon cancer epithelial cell line HCT-116, to block activities of NF- $\kappa$ B and activator protein-1 (AP-1) and had inhibitory effect on MMP-9 activation [35]. Moreover, it was reported that LPS stimulated NF- $\kappa$ B activation and promoted the invasiveness of pancreatic cancer cells by increasing MMP-9 mRNA expression [36]. Interestingly, in all these studies, MMP-9 was implicated in LPS-induced NF- $\kappa$ B activation-mediated downstream MMP gene regulation in diverse cancer cell types. However, the effect of LPS on NF- $\kappa$ B activation and related MMP regulation in prostate cancer have not been elucidated yet. In this respect, our novel findings show that LPS, a well-known TLR4 ligand, may affect NF- $\kappa \mathrm{B}$ signaling and downstream MMP gene regulation in $\mathrm{PC} 3$ prostate cancer cells.

In a limited number of studies, the role of MMP-8 and -10 were examined in prostate cancer cell proliferation, migration and invasion $[37,38]$. Nevertheless, previous studies have not addressed the relationship between NF- $\kappa$ B signaling and downstream gene regulation of MMP-8 and-10 in prostate cancer. For the first time, our study suggests that LPS-induced NF- $\kappa \mathrm{B}$ activation may contribute to the regulation of different classes of MMPs in PC3 prostate cancer cells.

Our study is the first to indicate inhibitory effect of doxycycline on the expression of MMPs in LPS-induced PC 3 human prostate cancer cells. Recent studies also showed that doxycycline inhibited activity of gelatinases and diminished tumor growth, invasion and metastasis in osteosarcoma, and lung, ovarian, cervical and oral cancer cell lines [39-42]. Similarly, zoledronate, which is nitrogen-containing bisphosphonate, exerts antitumoral effects by suppressing MMP expression and/or activity in various cancers $[43,44]$. Recently, we have also reported that zoledronate downregulated MMP-2 and -9 expression and activities in PC3 prostate cancer cells [45]. Although LPS caused the up-regulation of MMP-10 expression, doxycycline had no effect on MMP-10 expression in PC3 cells. In this respect, further studies may help to clarify the basis for the lack of inhibitory effect of doxycycline on MMP-10 expression in PC3 cells.

To enlighten the molecular mechanisms responsible for the inhibitory effect of doxycycline on MMPs in LPS-induced PC3 human prostate cancer cells, we also assessed the contribution of NF- $\kappa \mathrm{B}$ signaling to this effect. Interestingly, there are only a few studies regarding the effects of doxycycline on NF- $\kappa$ B-dependent MMP gene regulation. In one of the previous studies doxycycline was shown to inhibit phosphorylation and nuclear translocation of the NF- $\kappa \mathrm{B}-\mathrm{p} 65$ and NF- $\kappa$ B-induced MMP-9 expression in lung cancer cell migration and invasion [41]. In another study in human dermal fibroblasts doxycycline inhibited TNF- $\alpha$ -induced NF- $\kappa$ B-mediated MMP-2 expression but not MMP-9 expression [46]. Consistently with the results of these studies, we observed that inhibition of MMP-9 and -8 expression by doxycycline was associated with the down-regulation in the expression of NF- $\kappa \mathrm{B} / \mathrm{p} 65$, IKK $\beta$ and the reduction in the phosphorylation of $\mathrm{I} \kappa \mathrm{B}-\alpha$ in PC 3 prostate cancer cells. The inhibitory effect of doxycycline on IKK- $\beta$ expression was also supported by our IHC findings. Thus, the present study provides original evidence that down-regulation of MMPs, in particular MMP-9 and -8, caused by doxycycline may be associated with the inhibition of NF- $\kappa$ B signaling pathway in LPS-induced PC3 cells. 
In conclusion, our results indicate that doxycycline inhibits the expression of various MMPs and NF- $\kappa \mathrm{B}$ signaling may have a role in the regulation of the expression of MMPs in LPS-induced PC3 human prostate cancer cells. The results of the present study may help to clarify the cellular mechanisms of the inhibitory effect of doxycycline at subantimicrobial dose in LPS-induced PC3 cells and to encourage future use of doxycycline as an additional novel therapeutic agent in prostate cancer treatment.

\section{Author contributions}

DO performed the experiments. BR conceived and designed the experiments and wrote the paper. CGK designed the experiments. MZA and DO analyzed the results. MZA created the figures and formatted the manuscript. SCM and BUE performed immunohistochemical stainings and immunoscoring. All authors read and approved final manuscript.

\section{Conflict of interest}

The authors declare that they have no conflict of interests.

\section{Acknowledgment}

This research was supported by the Scientific Research Foundation of Ege University, Izmir, Turkey [12/ECZ/003 to Buket Reel].

\section{References}

1. Lokeshwar BL. MMP inhibition in prostate cancer.Ann NYAcad Sci. 1999;878:271-289. doi: 10.1111/j.1749-6632.1999.tb07690.x.

2. Lokeshwar BL. Chemically modified non-antimicrobial tetracyclines are multifunctional drugs against advanced cancers. Pharmacol Res. 2011;63:146-150. doi: 10.1016/j. phrs.2010.11.003.

3. Hassanipour-Azgomi S, Mohammadian-Hafshejani A, Ghoncheh M, Towhidi F, Jamehshorani S, Salehiniya H. Incidence and mortality of prostate cancer and their relationship with the Human Development Index worldwide. Prostate Int. 2016;4:118-124. doi: 10.1016/j.prnil.2016.07.001.

4. Duskova K, Vesely S. Prostate Specific Antigen. Current clinical application and future prospects. Biomed Pap Med Fac Univ Palacky Olomouc Czech Repub. 2014. doi: 10.5507/ bp.2014.046.

5. Mohammed AA. Biomarkers in prostate cancer: new era and prospective. Med Oncol (Northwood, London, England). 2014;31:140. doi: 10.1007/s12032-014-0140-3.

6. Cuzick J, Thorat MA, Andriole G et al. Prevention and early detection of prostate cancer. Lancet Oncol. 2014;15:e484 -e492. doi: 10.1016/s1470-2045(14)70211-6.

7. Kessenbrock K, Plaks V, Werb Z. Matrix metalloproteinases: regulators of the tumor microenvironment. Cell. 2010;141:52-67. doi: 10.1016/j.cell.2010.03.015.

8. Lu P, Weaver VM, Werb Z. The extracellular matrix: a dynamic niche in cancer progression. J Cell Biol. 2012;196:395-406. doi: $10.1083 /$ jcb.201102147.
9. Nagase H, Visse R, Murphy G. Structure and function of matrix metalloproteinases and TIMPs. Cardiovasc Res. 2006;69:562-573. doi: 10.1016/j.cardiores.2005.12.002.

10. Hadler-Olsen E, Winberg JO, Uhlin-Hansen L. Matrix metalloproteinases in cancer: their value as diagnostic and prognostic markers and therapeutic targets. Tumour Biol. 2013;34:2041-2051. doi: 10.1007/s13277-013-0842-8.

11. Sun J. Matrix metalloproteinases and tissue inhibitor of metalloproteinases are essential for the inflammatory response in cancer cells. J Signal Transduct. 2010;2010:985132. doi: $10.1155 / 2010 / 985132$.

12. Gialeli C, Theocharis AD, Karamanos NK. Roles of matrix metalloproteinases in cancer progression and their pharmacological targeting. FEBS J. 2011;278:16-27. doi: 10.1111/j.17424658.2010.07919.x.

13. Sapadin AN, Fleischmajer R. Tetracyclines: nonantibiotic properties and their clinical implications. J Am Acad Dermatol. 2006;54:258-265. doi: 10.1016/j.jaad.2005.10.004.

14. Bench TJ, Jeremias A, Brown DL. Matrix metalloproteinase inhibition with tetracyclines for the treatment of coronary artery disease. Pharmacol Res. 2011;64:561-566. doi: 10.1016/j. phrs.2011.05.002.

15. Saikali Z, Singh G. Doxycycline and other tetracyclines in the treatment of bone metastasis. Anticancer Drugs. 2003;14:773-778. doi: 10.1097/01.cad.0000099002.92896.cf.

16. Gu Y, Lee HM, Simon SR, Golub LM. Chemically modified tetracycline-3 (CMT-3): a novel inhibitor of the serine proteinase, elastase. Pharmacol Res. 2011;64:595-601. doi: 10.1016/j.phrs.2011.05.011.

17. Kaludercic N, Lindsey ML, Tavazzi B, Lazzarino G, Paolocci N. Inhibiting metalloproteases with PD 166793 in heart failure: impact on cardiac remodeling and beyond. Cardiovasc Ther. 2008;26:24-37. doi: 10.1111/j.1527-3466.2007.00034.x.

18. Gu Y, Walker C, Ryan ME, Payne JB, Golub LM. Non-antibacterial tetracycline formulations: clinical applications in dentistry and medicine.J Oral Microbiol. 2012;4. doi: 10.3402/ jom.v4i0.19227.

19. Jain G, Cronauer MV, Schrader M, Moller P, Marienfeld RB. NF-kappaB signaling in prostate cancer: a promising therapeutic target? World J Urol. 2012;30:303-310. doi: 10.1007/ s00345-011-0792-y.

20. Karin M. NF-kappaB as a critical link between inflammation and cancer. Cold Spring Harb Perspect Biol. 2009;1:a000141. doi: 10.1101/cshperspect.a000141.

21. Baud V, Karin M. Is NF-kappaB a good target for cancer therapy? Hopes and pitfalls. Nat Rev Drug Discov. 2009;8:33-40. doi: $10.1038 / \mathrm{nrd} 2781$.

22. Karin M. How NF-kappaB is activated: the role of the IkappaB kinase (IKK) complex. Oncogene. 1999;18:6867-6874. doi: 10.1038/sj.onc.1203219.

23. McCall P, Bennett L, Ahmad I et al. NFkappaB signalling is upregulated in a subset of castrate-resistant prostate cancer patients and correlates with disease progression. BrJ Cancer. 2012;107:1554-1563. doi: 10.1038/bjc.2012.372.

24. Nguyen DP, Li J, Yadav SS, Tewari AK. Recent insights into NF-kappaB signalling pathways and the link between inflammation and prostate cancer. BJU Int. 2014;114:168-176. doi: 10.1111/bju.12488.

25. Kim Y, Kang H, Jang SW, Ko J. Celastrol inhibits breast cancer cell invasion via suppression of NF-kB-mediated matrix metalloproteinase-9 expression. Cell Physiol Biochem. 2011;28:175-184. doi: 10.1159/000331729.

26. Pal S, Ganguly KK, Chatterjee A. Extracellular matrix protein fibronectin induces matrix metalloproteinases in human prostate adenocarcinoma cells PC-3. Cell Commun Adhes. 2013;20:105-114. doi: 10.3109/15419061.2013.833193. 
27. Ginzburg S, Golovine KV, Makhov PB, Uzzo RG, Kutikov A, Kolenko VM. Piperlongumine inhibits NF-kappaB activity and attenuates aggressive growth characteristics of prostate cancer cells. Prostate. 2014;74:177-186. doi: 10.1002/ pros.22739.

28. Hour MJ, Tsai SC, Wu HC et al. Antitumor effects of the novel quinazolinone MJ-33: inhibition of metastasis through the MAPK, AKT, NF-kappaB and AP-1 signaling pathways in DU145 human prostate cancer cells. Int J Oncol. 2012;41:1513-1519. doi: 10.3892/ijo.2012.1560.

29. Santa-Cecilia FV, Socias B, Ouidja MO et al. Doxycycline suppresses microglial activation by inhibiting the p38 MAPK and NF-kB signaling pathways. Neurotox Res. 2016;29:447-459. doi: 10.1007/s12640-015-9592-2.

30. Kanai K, Asano K, Hisamitsu T, Suzaki H. Suppression of matrix metalloproteinase-9 production from neutrophils by a macrolide antibiotic, roxithromycin, in vitro. Mediators Inflamm. 2004;13:313-319. doi: 10.1080/09629350400008810.

31. Kim HJ, Sung MK, Kim JS. Anti-inflammatory effects of glyceollins derived from soybean by elicitation with Aspergillus sojae. Inflamm Res. 2011;60:909-917. doi: 10.1007/s00011011-0351-4.

32. Fife RS, Sledge GW Jr, Roth BJ, Proctor C. Effects of doxycycline on human prostate cancer cells in vitro. Cancer Lett. 1998;127:37-41. doi: 10.1016/S0304-3835(98)00003-2.

33. Zhang D, Li YH, Mi M et al. Modified apple polysaccharides suppress the migration and invasion of colorectal cancer cells induced by lipopolysaccharide. Nutrition Res (NY). 2013;33:839-848. doi: 10.1016/j.nutres.2013.06.004.

34. Zhao Y, Kong X, Li X et al. Metadherin mediates lipopolysaccharide-induced migration and invasion of breast cancer cells. PLoS One. 2011;6:e29363. doi: 10.1371/journal.pone.0029363.

35. Lee SJ, Lim KT. UDN glycoprotein regulates activities of manganese-superoxide dismutase, activator protein-1, and nuclear factor-kappaB stimulated by reactive oxygen radicals in lipopolysaccharide-stimulated HCT-116 cells. Cancer Lett. 2007;254:274-287. doi: 10.1016/j.canlet.2007.03.009.

36. Ikebe M, Kitaura Y, Nakamura M et al. Lipopolysaccharide (LPS) increases the invasive ability of pancreatic cancer cells through the TLR4/MyD88 signaling pathway. J Surg Oncol. 2009;100:725-731. doi: 10.1002/jso.21392.

37. Singh S, Singh UP, Grizzle WE, Lillard JW Jr. CXCL12-CX-CR4 interactions modulate prostate cancer cell migration, metalloproteinase expression and invasion. Lab Invest. 2004;84:1666-1676. doi: 10.1038/labinvest.3700181.

38. Maruta S, Miyata Y, Sagara Y et al. Expression of matrix metalloproteinase-10 in non-metastatic prostate cancer: Correlation with an imbalance in cell proliferation and apoptosis. Oncol Lett. 2010;1:417-421. doi: 10.3892/ol_00000073.

39. Roomi MW, Kalinovsky T, Monterrey J, Rath M, Niedzwiecki A. In vitro modulation of MMP-2 and MMP-9 in adult human sarcoma cell lines by cytokines, inducers and inhibitors. Int J Oncol. 2013;43:1787-1798. doi: 10.3892/ijo.2013.2113.

40. Roomi MW, Monterrey JC, Kalinovsky T, Rath M, Niedzwiecki A. In vitro modulation of MMP-2 and MMP-9 in human cervical and ovarian cancer cell lines by cytokines, inducers and inhibitors. Oncol Rep. 2010;23:605-614. doi: 10.3892/or_00000675.

41. Zhao M, Gao Y, Wang L et al. Overexpression of integrin-linked kinase promotes lung cancer cell migration and invasion via NF-kappaB-mediated upregulation of matrix metalloproteinase-9. Int J Med Sci. 2013;10:995-1002. doi: 10.7150/ijms.5963.

42. Shen LC, Chen YK, Lin LM, Shaw SY. Anti-invasion and anti-tumor growth effect of doxycycline treatment for human oral squamous-cell carcinoma - in vitro and in vivo studies. Oral Oncol. 2010;46:178-184. doi: 10.1016/j.oraloncology.2009.11.013.

43. Dedes PG, Gialeli C, Tsonis AI et al. Expression of matrix macromolecules and functional properties of breast cancer cells are modulated by the bisphosphonate zoledronic acid. Biochim Biophys Acta. 2012;1820:1926-1939. doi: 10.1016/j. bbagen.2012.07.013.

44. Li XY, Lin YC, Huang WL et al. Zoledronic acid inhibits proliferation and impairs migration and invasion through downregulating VEGF and MMPs expression in human nasopharyngeal carcinoma cells. Med Oncol. (Northwood, London, England) 2012;29:714-720. doi: 10.1007/s12032-011-9904-1.

45. Reel B, Korkmaz CG, Arun MZ et al. The regulation of matrix metalloproteinase expression and the role of discoidin domain receptor $1 / 2$ signalling in zoledronate-treated PC 3 cells. J Cancer. 2015;6:1020-1029. doi: 10.7150/jca.12733.

46. Choi JY, Piao MS, Lee JB, Oh JS, Kim IG, Lee SC. Propionibacterium acnes stimulates pro-matrix metalloproteinase-2 expression through tumor necrosis factor-alpha in human dermal fibroblasts. J Invest Dermatol. 2008;128:846-854. doi: 10.1038/sj.jid.5701188.

Submitted: 21 March, 2016

Accepted after reviews: 21 November, 2016 Available as AoP: 29 November, 2016 